\title{
A new approach for time effect analysis in the settlement of single pile in nonlinear viscoelastic soil deposits*
}

\author{
Zhen-ya LI ${ }^{\dagger 1,2}$, Kui-hua WANG ${ }^{\dagger 1,2}$, Shu-hui LV ${ }^{1,2}$, Wen-bing WU ${ }^{3}$ \\ $\left({ }^{1}\right.$ MOE Key Laboratory of Soils and Geoenvironmental Engineering, Zhejiang University, Hangzhou 310058, China) \\ $\left({ }^{2}\right.$ Research Center of Coastal Urban Geotechnical Engineering, Zhejiang University, Hangzhou 310058, China) \\ ( ${ }^{3}$ Engineering Faculty, China University of Geosciences, Wuhan 430074, China) \\ †E-mail: jllizhenya@zju.edu.cn; zdwkh0618@zju.edu.cn
}

Received Oct. 26, 2014; Revision accepted June 1, 2015; Crosschecked July 15, 2015

\begin{abstract}
A new and simple approach is presented to analyze the time effect in the settlement of single pile and the distributions of pile shaft resistance and pile axial force. First, the viscosity of soil is considered by using a linear damper, and the nonlinear elasticity of pile lateral soil and pile end soil are simulated by using a hyperbola model and idealized elastoplastic model, respectively. Then, the settlement of the pile head, shaft resistance, and axial force along the pile are derived by virtue of a wave equation analysis program based on traveling wave decomposition. Based on the solutions, a parametric study has been undertaken to investigate the influences of the parameters of a pile-soil system on the settlement behavior of a single pile. Finally, the calculated results are compared with the measured results to demonstrate the effectiveness and accuracy of the proposed approach. Note that the presented solution allows for a good prediction of the settlement behavior of a single pile and can provide a reference for the preliminary design of a pile foundation.
\end{abstract}

Key words: Settlement, Time effect, Hyperbola mode, Idealized elastoplastic model, Viscosity, Wave equation analysis program doi: $10.1631 /$ jzus.A1400329

\section{Introduction}

The settlement of pile foundations is an important problem which concerns the safety and usability of buildings. As a result, a large amount of research has been devoted to this field and sophisticated calculation methods have been put forward, such as the elastic theory method (Poulos and Davis, 1968; Seo and Prezzi, 2007; Seo et al., 2009), load transfer method (Seed and Reese, 1957; Liu et al., 2004; Kim et al., 2007; Zhang et al., 2010; Zhang and Zhang, 2012), shear displacement method (Randolph and Wroth, 1978; Chow, 1989; Mylonakis and Gazetas,

\footnotetext{
ॠCorresponding author

* Project supported by the National Natural Science Foundation of China (Nos. 51378464 and 51309207)

(D) ORCID: Zhen-ya LI, http://orcid.org/0000-0002-6671-0326; Kuihua WANG, http://orcid.org/0000-0002-9362-0326

(c) Zhejiang University and Springer-Verlag Berlin Heidelberg 2015
}

1998), and various other numerical methods (Ai and Han, 2009; Comodromos et al., 2009; Said et al., 2009). However, these existing methods are primarily focused on the calculation of the final value of the settlement, rather than its time-varying behavior. In fact, the behavior of a pile under vertical load is a complex process of pile-soil interaction in which the load first transfers to pile lateral soil, then the pile shaft resistance occurs rapidly along with the settlement, and the pile tip resistance works consequently. As a result, the settlement behavior of a single pile is inevitably linked with time. Moreover, engineering practices show that the settlement of pile foundations in soft soil areas develops slowly, but continuously, within a long period of time after the construction is finished, due to the viscoelasticity of soft soils. For this reason, studying the time effect of the settlement of a single pile is not only theoretically significant but also valuable in engineering. 
During the past several years, a great effort has been made to study the time effect of settlement in a single pile. By converting the viscoelastic problem into an equivalent elastic problem by virtue of the Laplace transform, Booker and Poulos (1976) analyzed the long-term settlement of a pile in a soil exhibiting creep properties. Treating the pile-soil interaction as a time-dependent problem, Guo (2000) investigated the radial consolidation of the soil around a driven pile and the load-settlement response by considering the influence of the dissipation of pore pressure on the pile-soil stiffness, as well as the viscosity of soil. Bartolomei and Omel'chak (2003) investigated the pile's settlement behavior over time by using a mathematical model which took the viscoelastoplastic properties of soil into account. Danno and Kimura (2009) employed soil-water coupled analysis with the FEM-FDM method (namely finite element method and finite difference method) to evaluate the long-term displacement of pile installed in soft clayey ground and pointed out that the long-term settlement of the pile foundation due to vertical load could not be neglected, even if its bearing capacity was sufficient enough to resist the load in the short-term. Zhao et al. (2013) established the calculation formula for the settlement of a single-driven pile caused by the pile-side reconsolidation settlement based on the pile-soil interaction principle. On this basis, they found that the settlement of a single-driven pile could last for a very long time until it became stable. Feng et al. (2014), Hao and Dong (2014), and Yang et al. (2014) also investigated the time-effect settlement of bridge piles for the purpose of long-term settlement predictions of high-speed railway bridge pile foundations. All the above works indicate that the time effect of pile settlement is obvious.

Introducing the concept of time by considering the soil's linear viscoelastic properties, Wu et al. (2012) investigated the time effect of settlement of a single pile based on the virtual soil-pile model. However, the theoretical results coincided with the measured results only when the load acting on the pile head was small because of the small deformation and linear elasticity assumption. The solution they presented could only calculate the settlement of the pile head, making it impossible to analyze the load transfer mechanism of a pile.
In fact, the interaction between a pile and soil is nonlinear and various kinds of nonlinear load transfer models have been developed to simulate it. The hyperbola model was first proposed by Seed and Reese (1957) to simulate the load-transfer curves of pile lateral soil and fitted well with test results. Chin (1983) and Gupta $(2012$; 2013) have made the hyperbola model as a well-known model in plotting the behavior of piles. Broken line models were put forward by some researchers to obtain analytical solutions and for simplicity, such as the idealized elastoplastic model (Kezdi, 1965) and three broken line model (Guo, 2001). Previous studies showed that the load-settlement characteristics could be well analyzed by using the hyperbola model and broken line model to simulate pile lateral soil and pile end soil, respectively (Prevost and Hughes, 1981).

To obtain a better understanding of the time effect of single pile settlement, a new and simple approach is presented by means of a wave equation analysis program based on a traveling wave decomposition. The viscosity of soil is considered by using a linear damper, and the nonlinear elasticity of the pile lateral soil and pile end soil are simulated by a hyperbola model and idealized elastoplastic model, respectively. On this basis, the settlement behavior of a single pile is derived and the distributions of pile shaft resistance and pile axial forces are obtained accordingly.

\section{Pile-soil model and calculation principle}

\subsection{Schematic of pile-soil model}

The schematic diagram of a pile-soil model is shown in Fig. 1. The main assumptions employed in this study are: (1) the pile is linear elastic with a circular cross section; (2) the soil reactions acting on the pile shaft and pile tip are simulated by distributed Voigt models; (3) the load is applied on the pile head along the axial direction. The pile-soil system is divided into a total of $N$ layers numbered as $1,2, \ldots$, $i, \ldots, N$ with a total of $N+1$ nodes numbered as 0,1 , $2, \ldots, i, \ldots, N$ with $N$ going from pile head to pile tip. The time for the elastic wave to travel the length of one pile segment is defined as a time interval denoted by $\Delta t$. The properties of pile and soil layers are assumed to be homogeneous within each layer and 
the shaft resistance of each pile segment is assumed to be concentrated around the underside region of the segment. The displacement and velocity of the $i$ th node at the $j$ th time interval are denoted by $s(i, j)$ and $v(i, j)$, respectively. Then, the shaft resistance of the $i$ th pile segment can be expressed as

$$
R(i, j)=R_{\mathrm{s}}(i, j)+A(i) c(i) v(i, j),
$$

where $A(i)=2 \pi r(i) h(i)$ is the surface area of the $i$ th pile segment, $r(i)$ and $h(i)$ represent the radius and length of the $i$ th pile segment, respectively; $R_{\mathrm{s}}(i, j)=$ $\tau(i, j) A(i)$ denotes the static shaft resistance of the $i$ th pile segment, $\tau(i, j)$ is the shear stress of the soil acting on the surface of the $i$ th pile segment; and $c(i)$ is the damping coefficient of the $i$ th soil layer. According to Randolph and Deeks (1992), the value of $c(i)$ can be taken as $c(i)=G(i) / v_{\mathrm{s}}(i)$, where $G(i)=$ $\rho_{\mathrm{s}}(i)\left[v_{\mathrm{s}}(i)\right]^{2}$ is the shear modulus of the $i$ th soil layer, $\rho_{\mathrm{s}}(i)$ and $v_{\mathrm{s}}(i)$ are the mass density and the shear wave velocity of the $i$ th soil layer, respectively.

The soil reaction acting on the pile tip can be given as

$$
R_{\mathrm{toe}}(j)=R_{\mathrm{stoe}}(j)+A_{\mathrm{toe}} c_{\mathrm{toe}} v(N, j),
$$

where $A_{\text {toe }}$ and $v(N, j)$ denote the cross sectional area and the velocity of the pile tip, respectively; $R_{\text {stoe }}(j)$ is the static pile tip resistance; and $c_{\text {toe }}$ is the damping coefficient of the pile end soil. According to Randolph and Deeks (1992), the value of $c_{\text {toe }}$ can be taken as $c_{\text {toe }}=3.2 G_{\text {toe }} /\left[\pi\left(1-\mu_{\text {toe }}\right) v_{\text {stoe }}\right]$, where $G_{\text {toe }}=$ $\rho_{\text {stoe }}\left(v_{\text {stoe }}\right)^{2}$ is the shear modulus of pile end soil, $\rho_{\text {stoe }}$, $v_{\text {stoe, }}$, and $\mu_{\text {toe }}$ are the mass density, shear wave velocity, and Poisson's ratio of pile end soil, respectively.

As is shown in Fig. 2, the hyperbola model proposed by Wong and Teh (1995) is adopted here to simulate the relationship of the shear stress $\tau(i, j)$ and the relative displacement between the pile shaft and the surrounding soil.

$$
\tau(i, j)=\frac{s(i, j)}{\frac{1}{k_{\mathrm{s}}(i)}+R_{\mathrm{f}}(i) \frac{s(i, j)}{\tau_{\mathrm{f}}(i)}},
$$

where $k_{\mathrm{s}}(i)=G(i) /\left\{r(i) \ln \left[r_{\mathrm{m}}(i) / r(i)\right]\right\}$ is the initial shear stiffness of the pile-soil interface according to Ran- dolph and Wroth (1978), $r_{\mathrm{m}}(i)=2.5 l[1-\mu(i)]$ is the influence radius, $\mu(i)$ is the Poisson's ratio of the $i$ th soil layer; $R_{\mathrm{f}}(i)=\tau_{\mathrm{f}}(i) / \tau_{\text {ult }}(i)$ is the break ratio with an approximate value of $1, \tau_{\mathrm{ult}}(i)$ is the ultimate shear stress of pile-soil interface; and $\tau_{\mathrm{f}}(i)$ is the shear strength of the pile-soil interface which can be calculated by the following equation proposed by Chandler (1968): $\tau_{\mathrm{f}}(i)=k(i) \gamma(i) z \tan \varphi(i)$, where $z$ is the depth, $k(i)$ is the coefficient of the lateral pressure of the $i$ th soil layer, and $\gamma(i)$ and $\varphi(i)$ denote the unit weight and internal friction angle of the $i$ th soil layer, respectively. According to Jaky (1944), $k(i)=1-\sin \phi(i)$, where $\phi(i)$ is the effective angle of internal friction.

To calculate the static pile tip resistance $R_{\text {stoe }}(j)$, the idealized elastoplastic model shown in Fig. 3 is adopted to simulate the reaction of the pile end soil acting on the pile tip.

$$
R_{\text {stoe }}(j)= \begin{cases}k_{\text {toe }} s(N, j), & s(N, j)<s_{\mathrm{f}}, \\ R_{\text {stoef }}, & s(N, j) \geq s_{\mathrm{f}},\end{cases}
$$

where $k_{\text {toe }}, s_{\mathrm{f}}$, and $R_{\text {stoef }}$ denote stiffness, ultimate displacement, and ultimate resistance of the pile end soil in elastic stage, respectively. According to Randolph and Wroth (1978), the value of $R_{\text {stoef }}$ can be expressed as $R_{\text {stoef }}=k_{\text {toe }} S_{\mathrm{f}}$, where $k_{\mathrm{toe}}=8 G_{\mathrm{toe}} /[\pi(1-$ $\left.\left.\mu_{\mathrm{toe}}\right) d\right]$, and $d$ is the diameter of the pile tip.

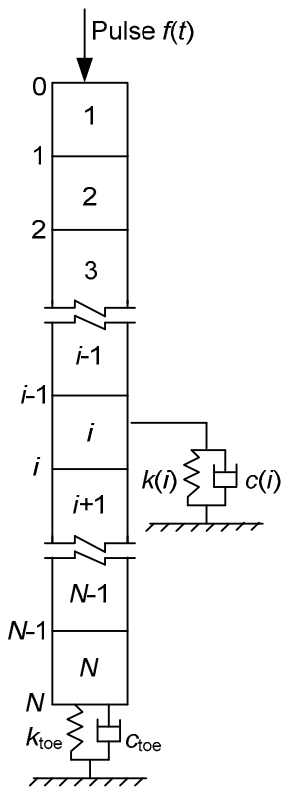

Fig. 1 Schematic diagram of a pile-soil model 


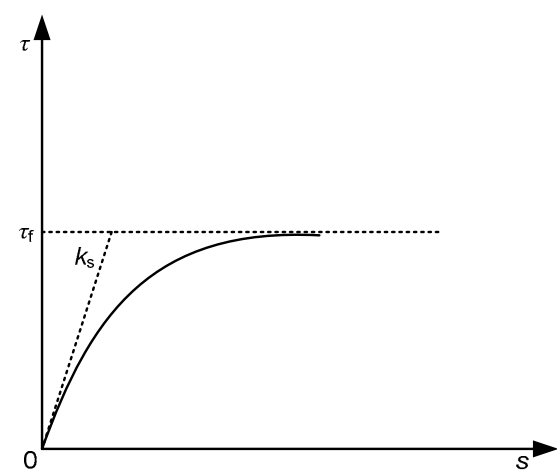

Fig. 2 Hyperbola model applied to simulate the nonlinear elasticity of pile lateral soil

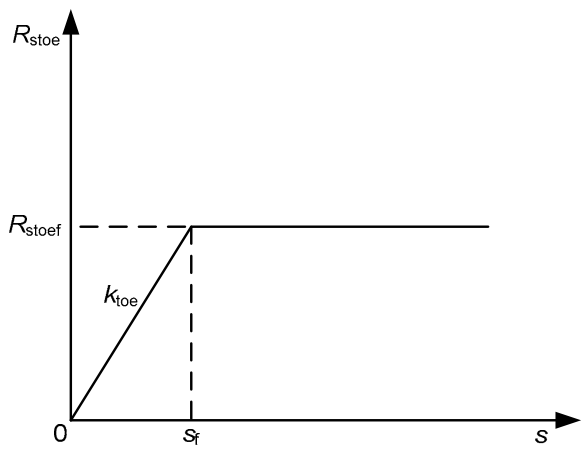

Fig. 3 Idealized elastoplastic model applied to simulate the nonlinear elasticity of the pile end soil

During the static pile load test, the time-varying load applied to the pile head can be expressed as Eq. (5) which is depicted in Fig. 4:

$$
f(t)= \begin{cases}\frac{q}{T_{1}} t, & t \leq T_{1}, \\ q, & T_{1}<t \leq T_{2},\end{cases}
$$

where $q$ is the maximum load, and $T_{1}$ and $T_{2}$ denote the moment when the load reaches its maximum and that when the loading is finished, respectively.

\subsection{Calculation principle of wave equation analy- sis program}

As is shown in Fig. 5, $R(i, j)$ is the shaft resistance of the $i$ th pile segment; the numbers 1 and 2 are employed to denote $P_{\mathrm{u}}^{+}(i, j)$ and $P_{\mathrm{d}}^{+}(i, j)$, which represent the upward and downward traveling wave of the upper interface of the $i$ th node at the $j$ th time interval, respectively; the numbers 3 and 4 are adopted to denote $P_{\mathrm{u}}^{-}(i, j)$ and $P_{\mathrm{d}}^{-}(i, j)$, which represent the upward and downward traveling wave of the lower interface of the $i$ th node at the $j$ th time interval, respectively. The acoustic impedance of the pile shaft is assumed to remain unchanged within each pile segment, and no distortion happens when elastic waves travel inside it. The upward traveling wave $P_{\mathrm{u}}^{+}(i+1, j-1)$ becomes $P_{\mathrm{u}}^{-}(i, j)$ when it travels from the tip to the head of the $i$ th segment in a time interval. Similarly, the downward traveling wave $P_{\mathrm{d}}^{-}(i, j-1)$ becomes $P_{\mathrm{d}}^{+}(i+1, j)$ when it travels from the head to the tip of the $i$ th segment in a time interval.

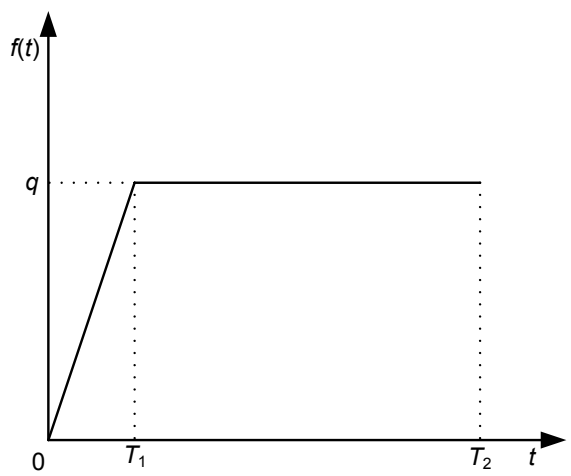

Fig. 4 Loading regime sketch
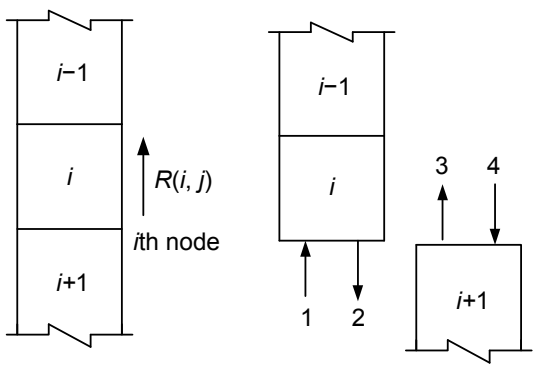

Fig. 5 Force analysis of each node

The acoustic impedance of the $i$ th pile segment is defined as $Z(i)$ and two dimensionless parameters are set as

$$
\begin{gathered}
T_{\mathrm{u}}(i)=Z(i) /[Z(i+1)+Z(i)], \\
T_{\mathrm{d}}(i)=Z(i+1) /[Z(i+1)+Z(i)] .
\end{gathered}
$$

Eqs. (8) and (9) can be obtained from the assumption that elastic waves do not distort when traveling inside each pile segment. 


$$
\begin{aligned}
& P_{\mathrm{u}}^{-}(i, j)=P_{\mathrm{u}}^{+}(i+1, j-1), \\
& P_{\mathrm{d}}^{+}(i, j)=P_{\mathrm{d}}^{-}(i-1, j-1) .
\end{aligned}
$$

The displacement of the $i$ th node at the $j$ th time interval can be obtained by means of the trapezoidal integration method:

$$
s(i, j)=s(i, j-1)+\frac{v(i, j)+v(i, j-1)}{2} \Delta t .
$$

The exciting pulse $f(t)$ applied to the pile head $(i=0)$ can be discretized at a time interval of $\Delta t$ and therefore yields

$$
P_{\mathrm{u}}^{-}(0, j)+P_{\mathrm{d}}^{-}(0, j)=f(j)
$$

The velocity of the pile head can be denoted as

$$
v(0, j)=\left[P_{\mathrm{d}}^{-}(0, j)-P_{\mathrm{u}}^{-}(0, j)\right] / Z(1)
$$

It can be obtained from Eq. (8) that:

$$
P_{\mathrm{u}}^{-}(0, j)=P_{\mathrm{u}}^{+}(1, j-1)
$$

Then, substituting Eqs. (11) and (13) into Eq. (12) leads to

$$
v(0, j)=\left[f(j)-2 P_{\mathrm{u}}^{+}(1, j-1)\right] / Z(1)
$$

From Eqs. (10) and (14), the displacement of the pile head at the $j$ th time interval can be expressed as

$$
\begin{aligned}
s(0, j)= & s(0, j-1)+\left[f(j)-2 P_{\mathrm{u}}^{+}(1, j-1)\right. \\
& +Z(1) v(0, j-1)] \Delta t /[2 Z(1)] .
\end{aligned}
$$

For the $i$ th node $(i=1,2, \ldots, N-1), P_{\mathrm{u}}^{+}(i, j)$ is made up of three parts as follows.

(1) Transmitted wave generated by $P_{\mathrm{u}}^{-}(i, j)$ :

$$
\begin{aligned}
P_{\mathrm{lu}}(i, j) & =\frac{2 Z(i)}{Z(i+1)+Z(i)} P_{\mathrm{u}}^{-}(i, j) \\
& =2 T_{\mathrm{u}}(i) P_{\mathrm{u}}^{+}(i+1, j-1) ;
\end{aligned}
$$

(2) Reflected wave generated by $P_{\mathrm{d}}^{+}(i, j)$ :

$$
\begin{aligned}
P_{2 \mathrm{u}}(i, j) & =\frac{Z(i+1)-Z(i)}{Z(i+1)+Z(i)} P_{\mathrm{d}}^{+}(i, j) \\
& =\left[T_{\mathrm{d}}(i)-T_{\mathrm{u}}(i)\right] P_{\mathrm{d}}^{-}(i-1, j-1) ;
\end{aligned}
$$

(3) Shaft resistance of the $i$ th pile segment:

$$
P_{3 \mathrm{u}}(i, j)=T_{\mathrm{u}}(i) R(i, j) .
$$

Accordingly, $P_{\mathrm{u}}^{+}(i, j)$ can be written as

$$
\begin{aligned}
P_{\mathrm{u}}^{+}(i, j)= & 2 T_{\mathrm{u}}(i) P_{\mathrm{u}}^{+}(i+1, j-1)+\left[T_{\mathrm{d}}(i)-T_{\mathrm{u}}(i)\right] \\
& \cdot P_{\mathrm{d}}^{-}(i-1, j-1)+T_{\mathrm{u}}(i) R(i, j) .
\end{aligned}
$$

Similarly, $P_{\mathrm{d}}^{-}(i, j)$ can be denoted as

$$
\begin{gathered}
P_{\mathrm{d}}^{-}(i, j)=2 T_{\mathrm{d}}(i) P_{\mathrm{d}}^{-}(i-1, j-1)+\left[T_{\mathrm{u}}(i)-T_{\mathrm{d}}(i)\right] \\
\cdot P_{\mathrm{u}}^{+}(i+1, j-1)-T_{\mathrm{d}}(i) R(i, j) .
\end{gathered}
$$

The velocity of the upper interface of the $i$ th node at the $j$ th time interval, $v^{+}(i, j)$, can be expressed as

$$
v^{+}(i, j)=\left[P_{\mathrm{d}}^{+}(i, j)-P_{\mathrm{u}}^{+}(i, j)\right] / Z(i) .
$$

From Eqs. (9), (19), and (21), we can obtain

$$
\begin{aligned}
v^{+}(i, j)=\{ & {\left[1-T_{\mathrm{d}}(i)+T_{\mathrm{u}}(i)\right] P_{\mathrm{d}}^{-}(i-1, j-1) } \\
& \left.-2 T_{\mathrm{u}}(i) P_{\mathrm{u}}^{+}(i+1, j-1)-T_{\mathrm{u}}(i) R(i, j)\right\} / Z(i) .
\end{aligned}
$$

Substituting Eqs. (6) and (7) into Eq. (22) gives

$$
v^{+}(i, j)=\frac{2\left[P_{\mathrm{d}}^{-}(i-1, j-1)-P_{\mathrm{u}}^{+}(i+1, j-1)\right]-R(i, j)}{Z(i+1)+Z(i)} .
$$

Similarly, the velocity of the lower interface of the $i$ th node at the $j$ th time interval, $v^{-}(i, j)$, can be obtained and is found to be equal to $v^{+}(i, j)$, which means that the velocity of the upper and the lower interface of the $i$ th node is continuous. As a result, the velocity of the $i$ th node at the $j$ th time interval can be derived as 


$$
v(i, j)=\frac{2\left[P_{\mathrm{d}}^{-}(i-1, j-1)-P_{\mathrm{u}}^{+}(i+1, j-1)\right]-R(i, j)}{Z(i+1)+Z(i)} .
$$

Combining Eqs. (1), (3), (10), and (24), the displacement and velocity of the $i$ th node $(i=1,2, \ldots$, $N-1$ ) can be rewritten as

$$
\begin{aligned}
s(i, j)= & \frac{-B(i)+\sqrt{[B(i)]^{2}+8 M(i) k_{\mathrm{s}}(i) R_{\mathrm{f}}(i) D(i)}}{4 M(i) k_{\mathrm{s}}(i) R_{\mathrm{f}}(i)}, \\
v(i, j)= & \frac{-B(i)+\sqrt{[B(i)]^{2}+8 M(i) k_{\mathrm{s}}(i) R_{\mathrm{f}}(i) D(i)}}{2 M(i) k_{\mathrm{s}}(i) R_{\mathrm{f}}(i) \Delta t} \\
& -\frac{2 s(i, j-1)+v(i, j-1) \Delta t}{\Delta t},
\end{aligned}
$$

where

$$
\begin{aligned}
B(i)= & 2 M(i) \tau_{\mathrm{f}}(i)-k_{\mathrm{s}}(i) R_{\mathrm{f}}(i)[2 M(i) s(i, j-1) \\
& +M(i) v(i, j-1) \Delta t+N(i) \Delta t-A(i) \Delta t], \\
M(i)= & A(i) c(i)+Z(i)+Z(i+1), \\
N(i)= & 2\left[P_{\mathrm{d}}^{-}(i-1, j-1)-P_{\mathrm{u}}^{+}(i+1, j-1)\right], \\
D(i)= & M(i) \tau_{\mathrm{f}}(i)[2 s(i, j-1)+v(i, j-1) \Delta t] \\
& +N(i) \tau_{\mathrm{f}}(i) \Delta t .
\end{aligned}
$$

For the $N$ th node (i.e., the pile tip), we can obtain

$$
P_{\mathrm{u}}^{+}(N, j)+P_{\mathrm{d}}^{+}(N, j)=R_{\mathrm{toe}}(j)+R(N, j) .
$$

The velocity of the $N$ th node can be derived as

$$
v(N, j)=\left[P_{\mathrm{d}}^{+}(N, j)-P_{\mathrm{u}}^{+}(N, j)\right] / Z(N) .
$$

According to Eq. (9), we can obtain

$$
P_{\mathrm{d}}^{+}(N, j)=P_{\mathrm{d}}^{-}(N-1, j-1) .
$$

From Eqs. (27)-(29), one obtains

$$
v(N, j)=\frac{2 P_{\mathrm{d}}^{-}(N-1, j-1)-\left[R_{\mathrm{toe}}(j)+R(N, j)\right]}{Z(N)} .
$$

Then, by Eqs. (1)-(4), (10), and (30), the displacement and velocity of the pile tip (i.e., the $N$ th node) can be rewritten as follows:
(1) When $s(N, j)<s_{\mathrm{f}}$,

$$
\begin{aligned}
& s(N, j)= \\
& \frac{-B+\sqrt{B^{2}+\left[8 M(N) k_{\mathrm{s}}(N) R_{\mathrm{f}}(N)+4 k_{\mathrm{toe}} R_{\mathrm{f}}(N) \Delta t\right] D}}{4 M(N) k_{\mathrm{s}}(N) R_{\mathrm{f}}(N)+2 k_{\mathrm{toe}} R_{\mathrm{f}}(N) \Delta t},
\end{aligned}
$$

$$
\begin{aligned}
& v(N, j)= \\
& \frac{-B+\sqrt{B^{2}+\left[8 M(N) k_{\mathrm{s}}(N) R_{\mathrm{f}}(N)+4 k_{\mathrm{toe}} R_{\mathrm{f}}(N) \Delta t\right] D}}{\Delta t\left[2 M(N) k_{\mathrm{s}}(N) R_{\mathrm{f}}(N)+k_{\mathrm{toe}} R_{\mathrm{f}}(N) \Delta t\right]} \\
& -\frac{2 s(N, j-1)+v(N, j-1) \Delta t}{\Delta t},
\end{aligned}
$$

where

$$
\begin{aligned}
& M(N)=Z(N)+A_{\mathrm{toe}} c_{\mathrm{toe}}+A(N) c(N), \\
& B=2 M(N) \tau_{\mathrm{f}}(N)+k_{\mathrm{toe}} \tau_{\mathrm{f}}(N) \Delta t-k_{\mathrm{s}}(N) R_{\mathrm{f}}(N) \\
& \cdot[2 M(N) s(N, j-1)+M(N) v(N, j-1) \Delta t \\
&\left.+2 P_{\mathrm{d}}^{-}(N-1, j-1) \Delta t-A(N) \Delta t\right], \\
& D= M(N) \tau_{\mathrm{f}}(N)[2 s(N, j-1)+v(N, j-1) \Delta t] \\
&+2 P_{\mathrm{d}}^{-}(N-1, j-1) \tau_{\mathrm{f}}(N) \Delta t .
\end{aligned}
$$

(2) When $s(N, j) \geq s_{\mathrm{f}}$,

$$
\begin{aligned}
s(N, j)= & \frac{-B_{\mathrm{s}}+\sqrt{B_{\mathrm{s}}^{2}+\left[8 M(N) k_{\mathrm{s}}(N) R_{\mathrm{f}}(N)\right] D_{\mathrm{s}}}}{4 M(N) k_{\mathrm{s}}(N) R_{\mathrm{f}}(N)}, \\
v(N, j)= & \frac{-B_{\mathrm{s}}+\sqrt{B_{\mathrm{s}}^{2}+\left[8 M(N) k_{\mathrm{s}}(N) R_{\mathrm{f}}(N)\right] D_{\mathrm{s}}}}{2 M(N) k_{\mathrm{s}}(N) R_{\mathrm{f}}(N) \Delta t} \\
& -\frac{2 s(N, j-1)+v(N, j-1) \Delta t}{\Delta t},
\end{aligned}
$$

where

$$
\begin{aligned}
B_{\mathrm{s}}= & 2 M(N) \tau_{\mathrm{f}}(N)+k_{\mathrm{toe}} \tau_{\mathrm{f}}(N) \Delta t-k_{\mathrm{s}}(N) R_{\mathrm{f}}(N) \\
& \cdot[2 M(N) s(N, j-1)+M(N) v(N, j-1) \Delta t \\
+ & \left.2 P_{\mathrm{d}}^{-}(N-1, j-1) \Delta t-R_{\mathrm{stoef}} \Delta t-A(N) \Delta t\right], \\
D_{\mathrm{s}}= & M(N) \tau_{\mathrm{f}}(N)[2 s(N, j-1)+v(N, j-1) \Delta t] \\
& +\tau_{\mathrm{f}}(N) \Delta t\left[2 P_{\mathrm{d}}^{-}(N-1, j-1)-R_{\text {stoef }}\right] .
\end{aligned}
$$

Up to now, equations of velocity, displacement, upward traveling wave, and downward traveling wave of each node have been given. However, these equations are correlated with each other. Therefore, iterations are needed to derive the displacement $s(i, j)$ when there is a load applied to the pile head. In particular, based on the settlement of the pile head at 
any moment, $s(0, j)$, the time effect of the settlement of a pile can be obtained.

According to Eq. (3), the shaft resistance of the $i$ th pile segment when the settlement is finished can be derived as

$$
\tau(i)=\frac{s(i)}{\frac{1}{k_{\mathrm{s}}(i)}+R_{\mathrm{f}}(i) \frac{s(i)}{\tau_{\mathrm{f}}(i)}} C(i),
$$

where $s(i)$ is the final displacement of the $i$ th node; $C(i)=2 \pi r(i)$ and denotes the circumference of the $i$ th pile segment.

Accordingly, the axial force of the $i$ th node can be given as

$$
F_{z}(i)=q-\sum_{1}^{i} \tau(i) h(i)
$$

Based on Eqs. (35) and (36), the distributions of the pile shaft resistance and pile axial force can be obtained.

In multi-stage loading, the load-settlement relation curve can be derived based on the final settlement of the pile head in each stage loading.

\section{Parametric study and discussion}

A comprehensive parametric study is conducted to analyze the time effect of the settlement of a single pile and the distributions of the pile shaft resistance and pile axial force. In the following analysis, pile lateral soil is assumed to be homogeneous to highlight the influences of the pile-soil parameters.

\subsection{Influence of the shear wave velocity of pile lateral soil on the settlement behavior of a single pile}

In this section, the applied load is $400 \mathrm{kN}$; the shear wave velocity of the pile lateral soil is $v_{\mathrm{s}}=100$, 120,140 , and $160 \mathrm{~m} / \mathrm{s}$. Other parameters of the pile and soil are given in Table 1 .

Fig. 6 shows the influence of the shear wave velocity of the pile lateral soil on the time effect of the settlement of a single pile, where $s$ is the settlement of the pile head, and $t$ is the time duration of the applied load. It can be seen that the settlement occurs rapidly when the load acts on the pile head and increases quickly with time, but gradually tends to be stable if the time is long enough. Note that both the stable value and the stable time of the settlement decrease with the increase of the shear wave velocity of the pile lateral soil but the decrease rate tends to be convergent.

Table 1 Properties of the pile and soil for the parametric study

\begin{tabular}{lccc}
\hline \multirow{2}{*}{ Parameter } & \multicolumn{3}{c}{ Description } \\
\cline { 2 - 4 } & Pile & $\begin{array}{c}\text { Pile lateral } \\
\text { soil }\end{array}$ & $\begin{array}{c}\text { Pile end } \\
\text { soil }\end{array}$ \\
\hline Length, $l(\mathrm{~m})$ & 20 & & \\
Radius, $r(\mathrm{~m})$ & 0.25 & & \\
Elastic wave velocity, & 4000 & & \\
$\quad v(\mathrm{~m} / \mathrm{s})$ & & & \\
Density, $\rho\left(\mathrm{kg} / \mathrm{m}^{3}\right)$ & 2500 & 1800 & 2000 \\
Shear wave velocity & & 100 & 150 \\
$\quad(\mathrm{~m} / \mathrm{s})$ & & \\
$\begin{array}{l}\text { Poisson's ratio, } \mu \\
\text { Internal friction angle, }\end{array}$ & & 0.4 & 0.4 \\
$\quad\left({ }^{\circ}\right)$ \\
$\begin{array}{c}\text { Coefficient of lateral } \\
\text { pressure, } k\end{array}$
\end{tabular}

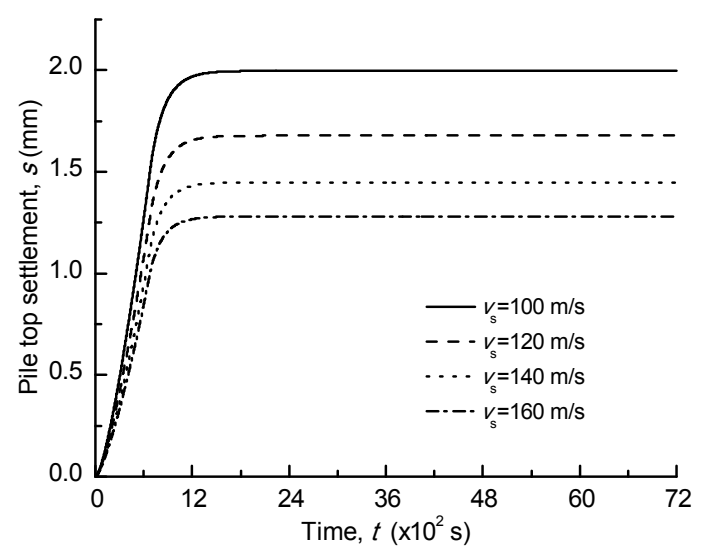

Fig. 6 Influence of the shear wave velocity of the pile lateral soil on the time effect of the settlement of a single pile

The influence of the shear wave velocity of the pile lateral soil on the distributions of the pile shaft resistance and pile axial force is shown in Fig. 7, where $\tau$ and $F_{z}$ represent pile shaft resistance and pile axial force, respectively; $H=0 \mathrm{~m}$ and $H=-20 \mathrm{~m}$ denote the positions of the pile head and the pile tip, 
respectively. Note that from Fig. 7 a the pile shaft resistance increases quickly with depth, but the increase rate tends to be convergent. It can also be seen that with the increase of the shear wave velocity of the pile lateral soil, the pile shaft resistance within the same depth increases and the location where the shaft resistance tends to be constant deepens. Fig. $7 \mathrm{~b}$ shows that pile axial force has a maximum value on the pile head and decreases with the depth due to the resistance of the pile lateral soil. It can also be seen that both the pile axial force and pile tip resistance decrease as the shear wave velocity of the pile lateral soil increases.
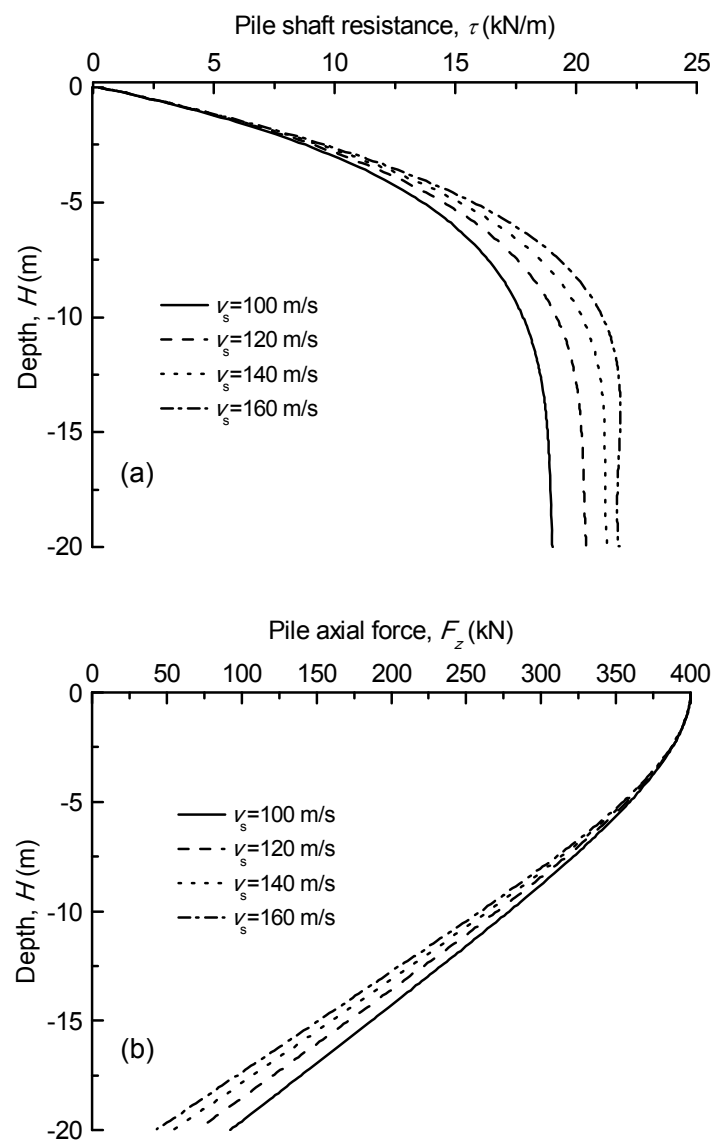

Fig. 7 Influence of the shear wave velocity of the pile lateral soil on the distributions of the pile shaft resistance (a) and pile axial force (b)

\subsection{Influence of the shear wave velocity of the pile end soil on the settlement behavior of a single pile}

Parameters used in this section are as follows: the applied load is $400 \mathrm{kN}$; the shear wave velocity of the pile end soil is $v_{\text {stoe }}=150,200,250$, and $300 \mathrm{~m} / \mathrm{s}$; other parameters of pile and soil are listed in Table 1.

Fig. 8 shows the influence of the shear wave velocity of the pile end soil on the time effect of settlement of a single pile. It can be seen that with the increase of the shear wave velocity of the pile end soil, both the stable time and the stable value of the settlement decrease but the decrease rate tends to be convergent. Due to the similar influence on the time effect of the settlement of a single pile to the pile lateral soil, the bearing stratum of the pile tip should be carefully chosen during the design of the pile foundations.

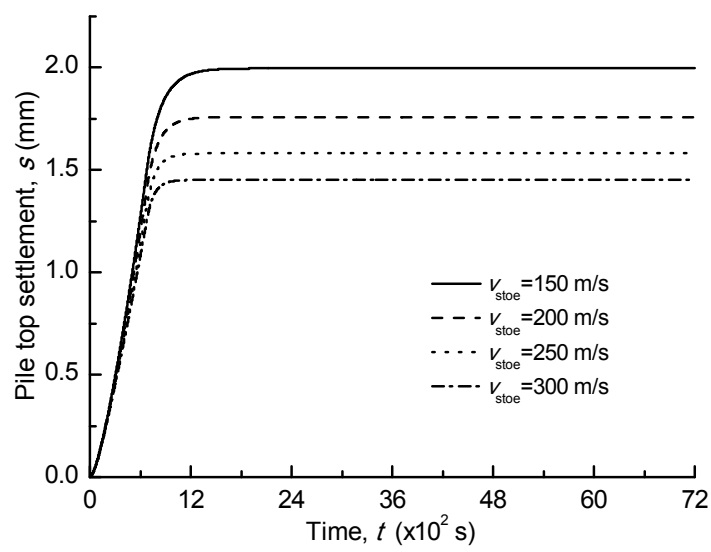

Fig. 8 Influence of the shear wave velocity of the pile end soil on the time effect of the settlement of a single pile

The influence of the shear wave velocity of the pile end soil on the distributions of the pile shaft resistance and pile axial force is shown in Fig. 9. Note that from Fig. 9a the pile shaft resistance increases quickly with depth, and the increase rate tends to be convergent until it reaches the maximum value. After reaching the maximum value, the shaft resistance corresponding to a smaller shear wave velocity of the pile end soil ( $v_{\text {stoe }}=150 \mathrm{~m} / \mathrm{s}$ in this case) tends to be constant, while that corresponding to a bigger shear wave velocity of the pile end soil decreases with depth and the decrease rate increases with the increase of the shear wave velocity of the pile end soil. It can also be seen that the pile shaft resistance within the same depth decreases as the shear wave velocity of the pile end soil increases. Fig. 9b shows that the pile axial force within the same depth 
increases with the increase of the shear wave velocity of the pile end soil.
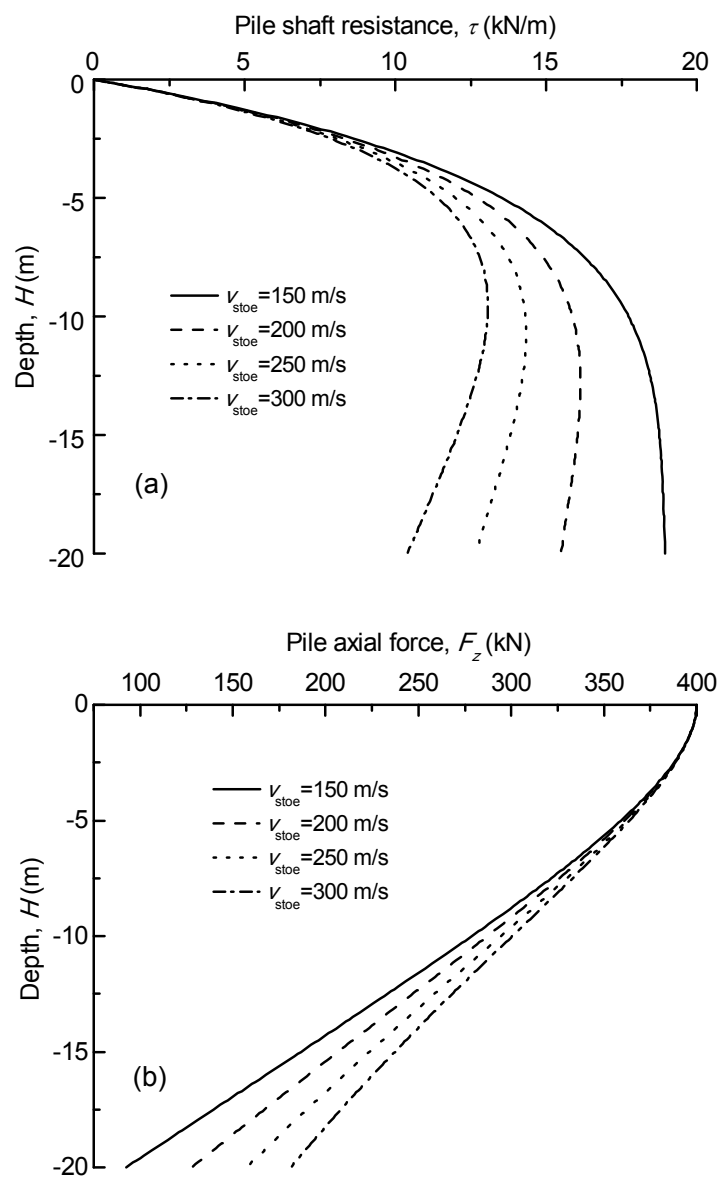

Fig. 9 Influence of the shear wave velocity of the pile end soil on the distributions of the pile shaft resistance (a) and pile axial force (b)

\subsection{Influence of the concrete strength grade on the settlement behavior of a single pile}

The concrete strength grade and elastic modulus $E_{\mathrm{p}}$ are given in Table 2 according to the national standard in China (MOHURD, 2010). In the following analysis, the influence of the concrete strength grade is reflected by the elastic wave velocity which is calculated according to the relation $v=\left(E_{\mathrm{p}} / \rho\right)^{1 / 2}$. The applied load is $400 \mathrm{kN}$, and the other soil-pile parameters in Table 1 are also adopted here.

Fig. 10 shows the influence of the concrete strength grade on the time effect of the settlement of a single pile. Note that the stable value of settlement decreases with the increase of the elastic modulus or concrete strength grade, but the decrease rate tends to be convergent. It can also be seen that if the concrete strength grade is large enough such as C50, further increase of the concrete strength grade has little influence on the stable value of the settlement, indicating that the settlement of a single pile can be effectively reduced by increasing the concrete strength grade just within a certain range. Fig. 10 also shows that the stable time of settlement is not affected by the concrete strength grade.

Table 2 Elastic modulus and concrete strength grade

\begin{tabular}{ccc}
\hline $\begin{array}{c}\text { Concrete strength } \\
\text { grade }\end{array}$ & $\begin{array}{c}\text { Elastic modulus, } \\
E_{\mathrm{p}}(\mathrm{GPa})\end{array}$ & $\begin{array}{c}\text { Elastic wave } \\
\text { velocity, } \boldsymbol{v}(\mathrm{m} / \mathrm{s})\end{array}$ \\
\hline $\mathrm{C} 20$ & 25.5 & 3194 \\
$\mathrm{C} 30$ & 30.0 & 3464 \\
$\mathrm{C} 40$ & 32.5 & 3606 \\
$\mathrm{C} 50$ & 34.5 & 3715 \\
$\mathrm{C} 60$ & 36.0 & 3795 \\
\hline
\end{tabular}

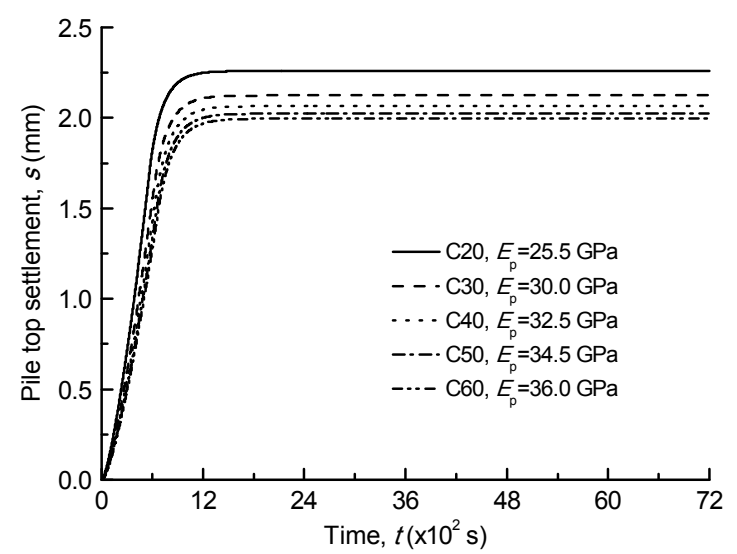

Fig. 10 Influence of the concrete strength grade on the time effect of the settlement of a single pile

The influence of the concrete strength grade on the distributions of the pile shaft resistance and pile axial force is shown in Fig. 11. It can be seen from Fig. 11a that the pile shaft resistance above a certain depth, namely $15 \mathrm{~m}$ below the ground surface, decreases with the increase of the concrete strength grade but the decrease rate tends to be convergent, while that below a certain depth increases as the concrete strength grade increases. The compressive deformation of the pile stem under the same load decreases with the increase of the concrete strength grade, as a result, the pile shaft resistance in the shallow position decreases accordingly and the applied load can transfer more to the deeper position. 
Fig. 11b shows that pile axial force within the same depth increases slightly with the increase of the concrete strength grade.
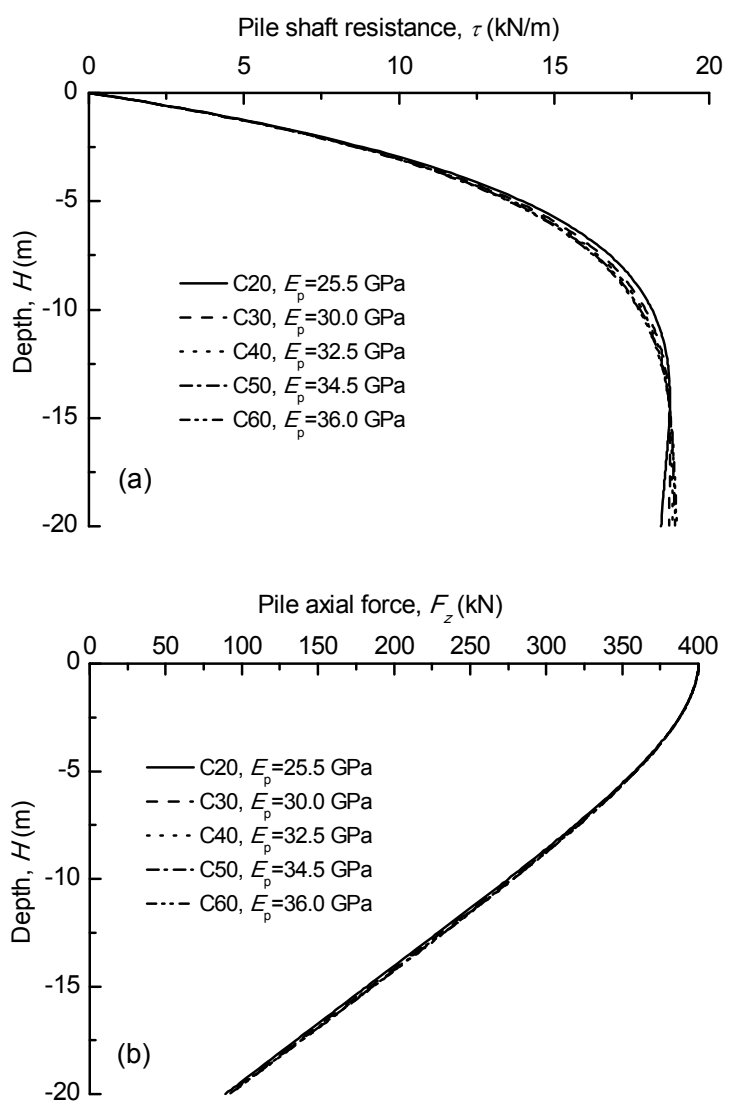

Fig. 11 Influence of the concrete strength grade on the distributions of the pile shaft resistance (a) and pile axial force (b)

\subsection{Influence of the ultimate displacement of the pile end soil in the elastic stage on the settlement behavior of a single pile}

In this section, the applied load is $800 \mathrm{kN}$; the ultimate displacement of the pile end soil in the elastic stage is $s_{\mathrm{f}}=2.0,2.5,3.0,3.5$, and $4.0 \mathrm{~mm}$; other parameters used herein are given in Table 1.

Fig. 12 shows the influence of the ultimate displacement of the pile end soil in the elastic stage on the time effect of the settlement of a single pile. As is shown in Fig. 12, in the initial phase when the applied load is small, the pile end soil remains in the elastic stage and the settlement curves corresponding to different $s_{\mathrm{f}}$ coincide completely with each other. However, the settlement curves separate out from the coincidence state gradually with the increase of the applied load, and the smaller the value of $s_{\mathrm{f}}$, the sooner the corresponding curve separates out. Moreover, the moment the settlement curve separates out from the coincidence state is the moment when the settlement of the pile tip reaches its ultimate value in the elastic stage. It can also be seen that with the increase of $s_{\mathrm{f}}$, both the stable time and stable value of the settlement decrease but the decrease rate tends to be convergent.

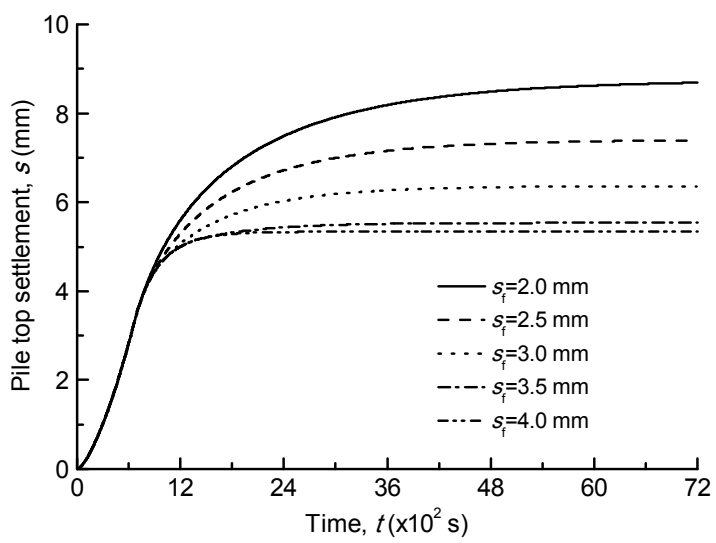

Fig. 12 Influence of the ultimate displacement of the pile end soil in the elastic stage on the time effect of the settlement of a single pile

The influence of the ultimate displacement of the pile end soil in the elastic stage on the distributions of the pile shaft resistance and pile axial force is shown in Fig. 13. It can be seen that with the increase of $s_{\mathrm{f}}$, the pile shaft resistance decreases but the pile axial force increases. It can also be seen that both the decrease rate of the pile shaft resistance and the increase rate of the pile axial force gradually tend to be convergent.

\section{Application in engineering}

To evaluate the reliability of the new approach employed in this study, a comparison with the measured load-settlement results from field tests is further conducted.

\subsection{Engineering example I}

This example is connected with a prestressed concrete pipe pile installed at a site on one of the 
heat-engine plants in Wenzhou, China. The length, diameter, wall thickness, and concrete strength grade of the pile were $45 \mathrm{~m}, 550 \mathrm{~mm}, 110 \mathrm{~mm}$, and C80, respectively. During the pile static load test, the maximum test load was $3300 \mathrm{kN}$, which had been divided into nine grades. The test load of the first grade was $620 \mathrm{kN}$ and the increment for each next grade was $310 \mathrm{kN}$. The pile-soil system was not completely destroyed after the test was finished. The detailed soil profiles and properties are given in Table 3.

Fig. 14 shows that the calculated results match well with the measured results during the entire process of loading, which may be attributed to the consideration of the nonlinear elasticity and viscosity of the pile lateral soil and pile end soil. Therefore, it can be seen that the model presented in this study allows a good prediction of the settlement of a single pile.
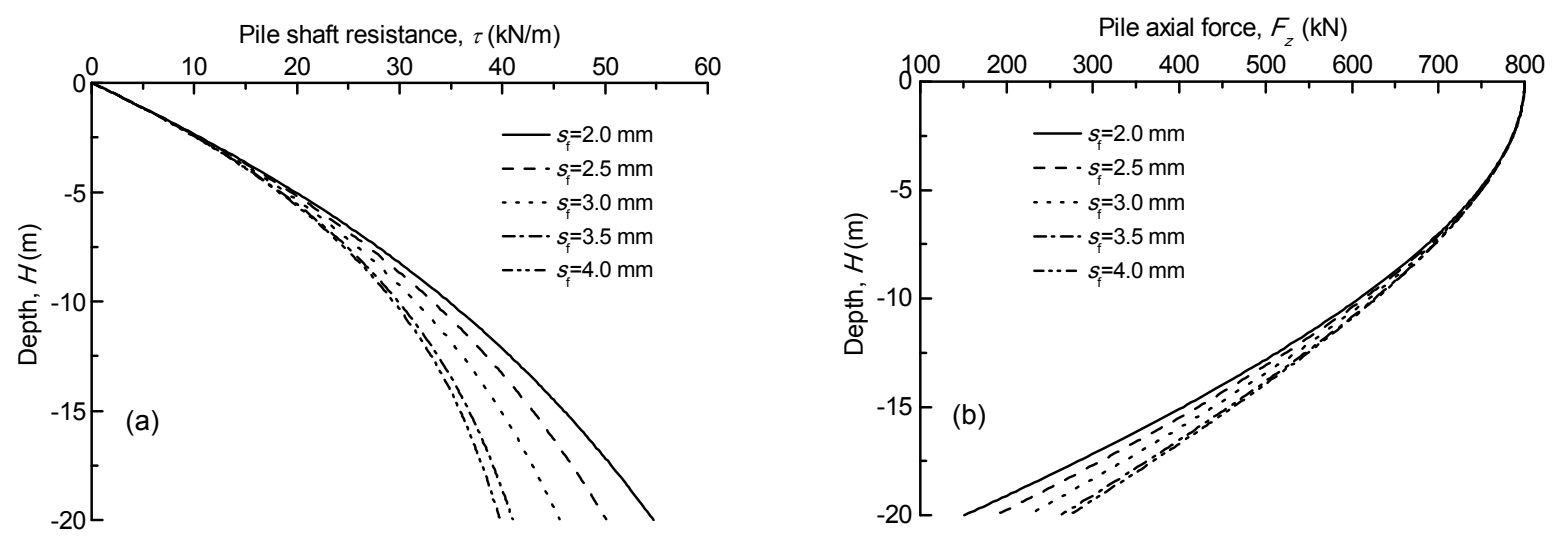

Fig. 13 Influence of the ultimate displacement of the pile end soil in the elastic stage on the distributions of the pile shaft resistance (a) and pile axial force (b)
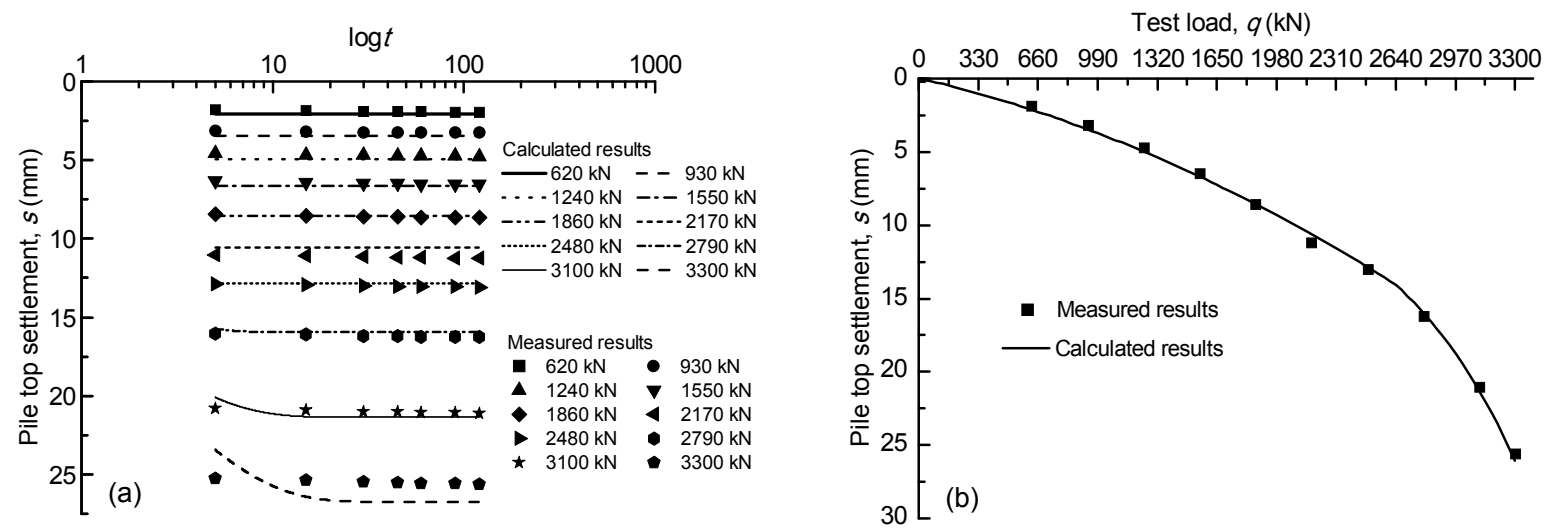

Fig. 14 Comparison of the calculated results and the measured results of $s$-logt curves (a) and load-settlement curves (b) for example I (unit of $t$ : min)

Table 3 Soil profiles and properties in the test site of example I

\begin{tabular}{clcccccc}
\hline $\begin{array}{c}\text { Layer } \\
\text { No. }\end{array}$ & \multicolumn{1}{c}{ Soil layer } & $\begin{array}{r}\text { Thickness of } \\
\text { soil layer }(\mathrm{m})\end{array}$ & $\begin{array}{c}\text { Density, } \rho_{\mathrm{s}} \\
\left(\mathrm{kg} / \mathrm{m}^{3}\right)\end{array}$ & $\begin{array}{c}\text { Shear wave ve- } \\
\text { locity, } \nu_{\mathrm{s}}(\mathrm{m} / \mathrm{s})\end{array}$ & $\begin{array}{c}\text { Internal friction } \\
\text { angle, } \varphi\left({ }^{\circ}\right)\end{array}$ & $\begin{array}{c}\text { Poisson's } \\
\text { ratio, } \mu\end{array}$ & $\begin{array}{c}\text { Lateral pressure } \\
\text { coefficient, } k\end{array}$ \\
\hline 1 & Backfill soil & 6 & 1800 & 95 & 17.2 & 0.38 & 0.57 \\
2 & Muck & 6 & 1788 & 123 & 10.9 & 0.45 & 0.66 \\
3 & Mucky soil & 8 & 1822 & 153 & 14.1 & 0.40 & 0.61 \\
4 & Mucky silty clay & 5 & 1789 & 192 & 12.3 & 0.42 & 0.65 \\
5 & Silty clay & 15 & 1880 & 241 & 18.9 & 0.35 & 0.52 \\
6 & Silt & 15 & 1920 & 254 & 23.8 & 0.30 & 0.43 \\
& & & & & & $\left(s_{\mathrm{f}}=5.3 \mathrm{~mm}\right)$ \\
\hline
\end{tabular}




\subsection{Engineering example II}

This example is connected with a prestressed concrete pipe pile installed at a site on one of the heat-engine plants in Huzhou, China. The length, diameter, wall thickness, and concrete strength grade of the pile were $22 \mathrm{~m}, 500 \mathrm{~mm}, 100 \mathrm{~mm}$, and C80, respectively. During the pile static load test, the maximum test load was $1800 \mathrm{kN}$, which had been divided into nine grades. The test load of the first grade was $360 \mathrm{kN}$ and the increment for each next grade was $180 \mathrm{kN}$. The pile-soil system was not completely destroyed after the test was finished. The detailed soil profiles and properties are given in Table 4.

As can be seen in Fig. 15, the comparison between the calculated results and the measured results shows altitudinal consistency.

\section{Conclusions}

1. By using the dashpot to consider the viscosity of soil, and by means of a hyperbola model and idealized elastoplastic model to simulate the nonlinear elasticity of pile lateral soil and pile end soil, respectively, a new approach is proposed, which can not only analyze the time effect of the settlement of a single pile but also obtain the distributions of the pile shaft resistance and pile axial force.

2 . The settlement occurs rapidly as the load acts on the pile head and increases quickly with time, but gradually tends to be stable if the time is long enough, indicating that the time effect of settlement of a single pile is quite obvious. Parametric studies show that soil parameters have a more significant influence on the settlement behavior of a single pile than the concrete strength grade of the pile body. As a result, it is of great importance to choose proper bearing stratum and concrete strength grade during the design of pile foundations for the requirement of safety, rationality, and economics.

3. The comparison of the calculated results and the measured results shows that the approach presented in this paper is effective to simulate the settlement behavior of single piles driven in multilayered soils.

Table 4 Soil profiles and properties in the test site of example II

\begin{tabular}{clcccccc}
\hline $\begin{array}{c}\text { Layer } \\
\text { No. }\end{array}$ & \multicolumn{1}{c}{ Soil layer } & $\begin{array}{c}\text { Thickness of } \\
\text { soil layer }(\mathrm{m})\end{array}$ & $\begin{array}{c}\text { Density, } \rho_{\mathrm{s}} \\
\left(\mathrm{kg} / \mathrm{m}^{3}\right)\end{array}$ & $\begin{array}{c}\text { Shear wave ve- } \\
\text { locity, } v_{\mathrm{s}}(\mathrm{m} / \mathrm{s})\end{array}$ & $\begin{array}{c}\text { Internal friction } \\
\text { angle, } \varphi\left(^{\circ}\right)\end{array}$ & $\begin{array}{c}\text { Poisson's } \\
\text { ratio, } \mu\end{array}$ & $\begin{array}{c}\text { Lateral pressure } \\
\text { coefficient, } k\end{array}$ \\
\hline 1 & Backfill soil & 5 & 1800 & 97 & 16.2 & 0.40 & 0.59 \\
2 & Silty clay & 2 & 1867 & 102 & 18.9 & 0.35 & 0.53 \\
3 & Silt & 3 & 1852 & 136 & 20.6 & 0.30 & 0.50 \\
4 & Clay & 8 & 1853 & 150 & 15.5 & 0.41 & 0.58 \\
5 & $\begin{array}{l}\text { Silty clay mixed } \\
\text { with silt }\end{array}$ & 8 & 1835 & 163 & 19.5 & 0.32 & 0.52 \\
& & & & & & \\
$\left(s_{\mathrm{f}}=11 \mathrm{~mm}\right)$
\end{tabular}

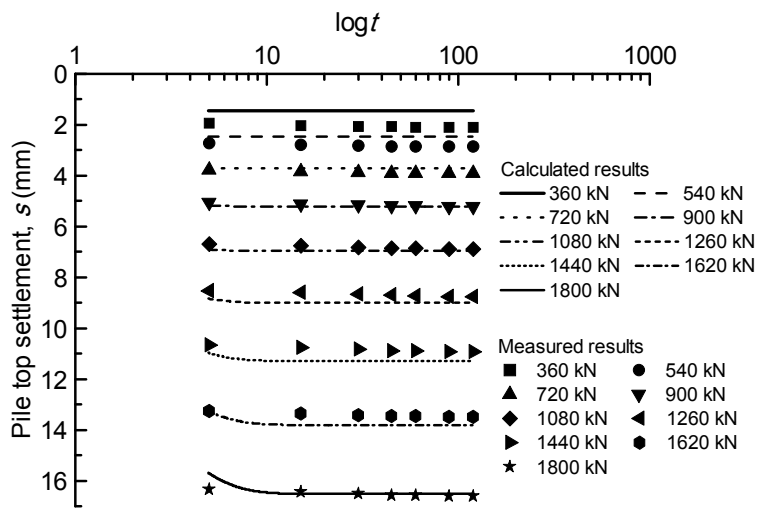

(a)

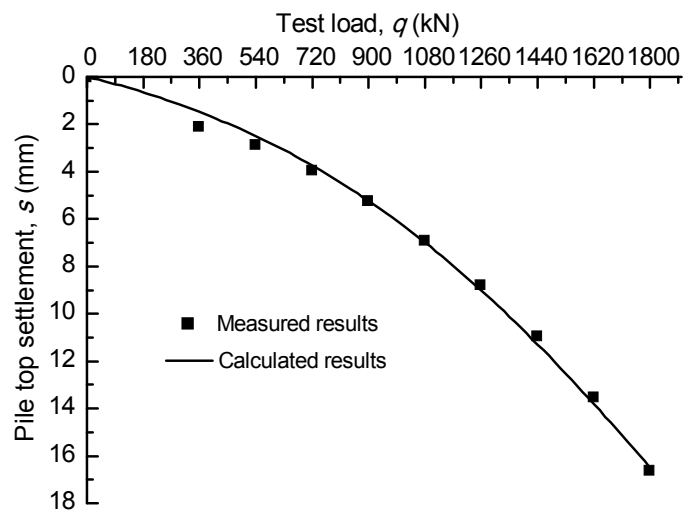

(b)

Fig. 15 Comparison of the calculated results and the measured results of $s$-logt curves (a) and load-settlement curves (b) for example II (unit of $t$ : min) 


\section{References}

Ai, Z.Y., Han, J., 2009. Boundary element analysis of axially loaded piles embedded in a multi-layered soil. Computers and Geotechnics, 36(3):427-434. [doi:10. 1016/j.compgeo.2008.06.001]

Bartolomei, A.A., Omel'chak, I.M., 2003. Effect of loading character on analysis of pile and pile-foundation settlements. Soil Mechanics and Foundation Engineering, 40(5):153-160. [doi:10.1023/B:SMAF.0000010108.32137. c7]

Booker, J.R., Poulos, H.G., 1976. Analysis of creep settlement of pile foundations. Journal of the Geotechnical Engineering Division, 102(1):1-14.

Chandler, R.J., 1968. The shaft friction of piles in cohesive soils in terms of effective stress. Civil Engineering and Public Works Review, 63(738):48-51.

Chin, F.K., 1983. Bilateral plate bearing tests. Proceedings of International Symposium on in situ Testing, Paris, France, p.29-33.

Chow, Y.K., 1989. Axially loaded piles and pile groups embedded in a cross-anisotropic soil. Géotechnique, 39(2):203-212. [doi:10.1680/geot.1989.39.2.203]

Comodromos, E.M., Papadopoulou, M.C., Rentzeperis, I.K., 2009. Pile foundation analysis and design using experimental data and 3-D numerical analysis. Computers and Geotechnics, 36(5):819-836. [doi:10. 1016/j.compgeo.2009.01.011]

Danno, K., Kimura, M., 2009. Evaluation of long-term displacements of pile foundation using coupled FEM and centrifuge model test. Soils and Foundations, 49(6): 941-958. [doi:10.3208/sandf.49.941]

Feng, S.Y., Wei, L.M., He, C.Y., et al., 2014. A computational method for post-construction settlement of high-speed railway bridge pile foundation considering soil creep effect. Journal of Central South University, 21(7):29212927. [doi:10.1007/s11771-014-2258-z]

Guo, W.D., 2000. Visco-elastic consolidation subsequent to pile installation. Computers and Geotechnics, 26(2):113144. [doi:10.1016/S0266-352X(99)00028-2]

Guo, W.D., 2001. Pile capacity in nonhomogeneous softening soil. Soils and Foundations, 41(2):111-120. [doi:10. 3208/sandf.41.2_111]

Gupta, R.C., 2012. Hyperbolic model for load tests on instrumented drilled shafts in intermediate geomaterials and rock. Journal of Geotechnical and Geoenvironmental Engineering, 138(11):1407-1414. [doi:10.1061/(ASCE) GT.1943-5606.0000697]

Gupta, R.C., 2013. Load-settlement behavior of drilled shafts in multilayered deposits of soils and intermediate geomaterials. Geotechnical Testing Journal, 36(5):1-17. [doi:10.1520/GTJ20130016]

Hao, J., Dong, J., 2014. Study on application of Asaoka method on settlement prediction of pile foundation for high speed railway bridges. Proceedings of the 10th Asia Pacific Transportation Development Conference, Beijing, China, p.671-676. [doi:10.1061/9780784413364.082]

Jaky, J., 1944. The coefficient of earth pressure at rest. Journal of the Society of Hungarian Architects and Engineers, 78(22):355-358.

Kezdi, S., 1965. Bearing mechanism of piles. Géotechnique, 20(1):1-5 (in Japanese).

Kim, H.J., Mission, J.L.C., Park, I.S., 2007. Analysis of static axial load capacity of single piles and large diameter shafts using nonlinear load transfer curves. KSCE Journal of Civil Engineering, 11(6):285-292. [doi:10. 1007/BF02885899]

Liu, J., Xiao, H.B., Tang, J., et al., 2004. Analysis of loadtransfer of single pile in layered soil. Computers and Geotechnics, 31(2):127-135. [doi:10.1016/j.compgeo. 2004.01.001]

MOHURD (Ministry of Housing and Urban-Rural Development), 2010. Code for Design of Concrete Structures, GB50010-2010. China Architecture \& Building Press, China (in Chinese).

Mylonakis, G., Gazetas, G., 1998. Settlement and additional internal forces of grouped piles in layered soil. Géotechnique, 48(1):55-72. [doi:10.1680/geot.1998.48. $1.55]$

Poulos, H.G., Davis, E.H., 1968. The settlement behaviour of single axially loaded incompressible piles and piers. Géotechnique, 18(3):351-371. [doi:10.1680/geot.1968. 18.3.351]

Prevost, J.H., Hughes, T.J.R., 1981. Finite-element solution of elastic-plastic boundary-value problems. Journal of Applied Mechanics, 48(1):69-74. [doi:10.1115/1.3157594]

Randolph, M.F., Wroth, C.P., 1978. Analysis of deformation of vertically loaded piles. Journal of the Geotechnical Engineering Division, 104(12):1465-1488.

Randolph, M.F., Deeks, A.J., 1992. Dynamic and static soil models for axial pile response. Proceedings of the 4th International Conference on the Application of Stress Wave Theory to Piles, the Hague, the Netherlands, p.2124.

Said, I., de Gennaro, V., Frank, R., 2009. Axisymmetric finite element analysis of pile loading tests. Computers and Geotechnics, 36(1-2):6-19. [doi:10.1016/j.compgeo. 2008.02.011]

Seed, H.B., Reese, L.C., 1957. The action of soft clay along friction piles. American Society of Civil Engineers Transactions, 122(1):731-754.

Seo, H., Prezzi, M., 2007. Analytical solutions for a vertically loaded pile in multilayered soil. Geomechanics and Geoengineering, 2(1):51-60. [doi:10.1080/17486020601 099380]

Seo, H., Basu, D., Prezzi, M., et al., 2009. Load-settlement response of rectangular and circular piles in multilayered 
soil. Journal of Geotechnical and Geoenvironmental Engineering, 135(3):420-430. [doi:10.1061/(ASCE) 1090-0241(2009)135:3(420)]

Wong, K.S., Teh, C.I., 1995. Negative skin friction on piles in layered soil deposits. Journal of Geotechnical Engineering, 121(6):457-465. [doi:10.1061/(ASCE)07339410(1995)121:6(457)]

Wu, W.B., Wang, K.H., Zhang, Z.Q., et al., 2012. A new approach for time effect analysis of settlement for single pile based on virtual soil-pile model. Journal of Central South University, 19(9):2656-2662. [doi:10.1007/ s11771-012-1324-7]

Yang, Q., Leng, W.M., Zhang, S., et al., 2014. Long-term settlement prediction of high-speed railway bridge pile foundation. Journal of Central South University, 21(6): 2415-2424. [doi:10.1007/s11771-014-2195-x]

Zhang, Q.Q., Zhang, Z.M., 2012. A simplified nonlinear approach for single pile settlement analysis. Canadian Geotechnical Journal, 49(11):1256-1266. [doi:10.1139/ t11-110]

Zhang, Q.Q., Zhang, Z.M., He, J.Y., 2010. A simplified approach for settlement analysis of single pile and pile groups considering interaction between identical piles in multilayered soils. Computers and Geotechnics, 37(7-8): 969-976. [doi:10.1016/j.compgeo.2010.08.003]

Zhao, C.Y., Leng, W.M., Zheng, G.Y., 2013. Calculation and analysis for the time-dependency of settlement of the single-driven pile in double-layered soft clay. Applied Clay Science, 79:8-12. [doi:10.1016/j.clay.2013.02.022]

\section{中文概要}

题 目: 非线性粘弹性土中单桩沉降时间效应分析新方法

目 的: 提出一种新的简便方法, 计算非线性土中单桩 沉降的时间效应以及沉降稳定之后桩身侧摩阻 力和桩身轴力的分布情况, 为桩基础的设计提 供参考。

创新点: 1. 考虑土体的非线性（包括桩侧土和桩端土）, 计算结果更接近实际情况; 2. 采用基于行波分 解的波动分析程序, 计算桩身任意位置处的沉 降, 并据此计算任意位置处的侧摩阻力和桩身 轴力; 3. 该方法既可以用于分析单桩沉降的时 间效应, 也可以计算不同加载等级下桩的最终 沉降量, 为设计提供参考。

方 法: 1. 采用线性阻尼器模拟土体的粘性, 双曲线模 型和理想弹塑性模型分别模拟桩侧土和桩端土 的非线性，采用基于行波分解的波动分析程序 得到桩身不同位置处的沉降、侧摩阻力及轴力 计算公式（式(15)、(25)、(31)、(33)、(35)和 (36))；2. 分析在不同桩土参数情况下，桩顶沉 降随时间的变化规律（图 6、8、10 和 12) 及桩 身侧摩阻力和桩身轴力分布情况（图 7、9、11 和 13); 3. 将计算结果与工程实测结果进行对 比, 以验证理论模型的可行性 (图 14 和 15)。

结 论: 1. 单桩沉降的时间效应非常显著, 并受到桩土 参数的影响; 2. 本文提出的方法能够较准确地 模拟工程实际情况。

关键词: 沉降; 时间效应; 双曲线模型; 理想弹塑性模 型; 波动分析程序 